\title{
Guest Editorial: Symposium on Clubfoot
}

\author{
Rujuta Mehta ${ }^{1}$, Alaric Aroojis ${ }^{2}$, Nirmal R Gopinathan ${ }^{3}$ \\ Journal of Foot and Ankle Surgery (Asia Pacific) (2021): 10.5005/jp-journals-10040-1174
}

\section{"The human foot is a masterpiece of engineering and a work of art"} - Leonardo da Vinci

The foot, with 26 bones and $>30$ articulations, has been a subject of much fascination as an apparatus for bipedal human locomotion. Clubfoot is a congenital deformation of the child's foot that has intrigued the medical fraternity since antiquity. It has been well-represented in art and literature through the ages and is one of the most widely discussed and researched subjects in the field of Medicine since the time of Hippocrates. Yet, few conditions have witnessed as great a paradigm shift in concepts and treatment over the last few decades as clubfoot treatment has with the advent of the Ponseti technique. While the Ponseti method has been widely accepted for the treatment of idiopathic clubfoot in the young infant, there is still a lack of consensus on bracing protocols, validated outcome measures to report long-term results, the role of the Ponseti method in treating non-idiopathic clubfoot and clubfoot in the older walking-age child, to name a few.

When we were invited to helm this Special Issue dedicated to Clubfoot, we made a conscious decision not to skirt around these controversial topics, but rather to dive right into them. Our aim was not to focus on well-hashed principles and results of the Ponseti method, but rather to highlight lesser known aspects of clubfoot treatment that have eluded the limelight so far. To achieve this, we sought out doyens in the field of clubfoot-Dr Shafique Pirani, Dr Norgrove Penny, Dr David Spiegel, and many others who have brought about a global change in the treatment of clubfoot and maximized its reach through public health platforms, to join our panel of authors. The other contributing authors are among the leading pediatric orthopedic surgeons from the Indian subcontinent, who have a deep interest in the subject and significant experience in the field.

The symposium begins with a personal memoir by Dr Pirani; which is a priceless gem of history describing his early adoption of the Ponseti method when surgery for clubfoot was still fashionable, his in-depth research into the finer nuances of cartilage remodeling and joint re-orientation following serial casting, and his prescient prediction that this method would be eminently adaptable to a global public healthcare approach. Using history as a springboard, the symposium takes a leap into a burning problem common to low- and middle-income countries-how to manage delayed presenting clubfoot in the walking-age child. Dr Norgrove Penny, a global clubfoot expert who was instrumental in initiating the Uganda Sustainable Clubfoot Care Project along with Dr Pirani and who has immense experience in treating neglected clubfeet in Africa, very elegantly reviews this difficult problem by approaching it in a methodical fashion written in his inimitable lucid and crisp style. The next two reviews by Indian authors delve into the more challenging varieties of clubfoot-the syndromic and recurrent feet, where there is a refreshing change in both perceptions and prospects. The section on bracing in clubfoot is a detailed and informative outline, summing up the constantly improved newer designs and varieties of braces that are so integral to the maintenance of clubfoot correction. The final
${ }^{1}$ Department of Paediatric Orthopaedics, Bai Jerbai Wadia Hospital for Children, Mumbai, Maharashtra, India; Consultant Paediatric Orthopaedic and Paediatric Hand Surgeon, Nanavati Max Super Speciality Hospital, Jaslok Hospital and Medical Research Center, Shushrusha Citizens' Co-Op Hospital, Surya Child Care and KLS Memorial Hospital, Mumbai, Maharashtra, India

${ }^{2}$ Consultant Paediatric Orthopaedic Surgeon, Lilavati Hospital, PD Hinduja Hospital, Hinduja Healthcare and Bai Jerbai Wadia Hospital for Children, Mumbai, Maharashtra, India

${ }^{3}$ Orthopaedics (Paediatric Orthopaedics), Postgraduate Institute of Medical Education and Research, Chandigarh, India

Corresponding Author: Alaric Aroojis, Consultant Paediatric Orthopaedic Surgeon, Lilavati Hospital, PD Hinduja Hospital, Hinduja Healthcare and Bai Jerbai Wadia Hospital for Children, Mumbai, Maharashtra, India, Phone: +91 9320284402, e-mail: aaroojis@gmail.com How to cite this article: Mehta R, Aroojis A, Gopinathan NR. Guest Editorial: Symposium on Clubfoot. J Foot Ankle Surg (Asia Pacific) 2021;8(3):93.

Source of support: Nil

Conflict of interest: None

highlight of the symposium is an eye-opening narrative review on various outcome tools by Dr David Spiegel-measures and scores which faithfully report the litmus test of correction, namely, patientcentric outcomes. In addition, we have put together two video techniques of commonly performed surgical procedures which are of benefit in treating the challenging clubfoot.

As Matsuo Basho has rightly said, our journey has just begun and we are hopefully on a firm "footing" with this special issue that attempts to throw light on the ever-changing vicissitudes of clubfoot treatment.

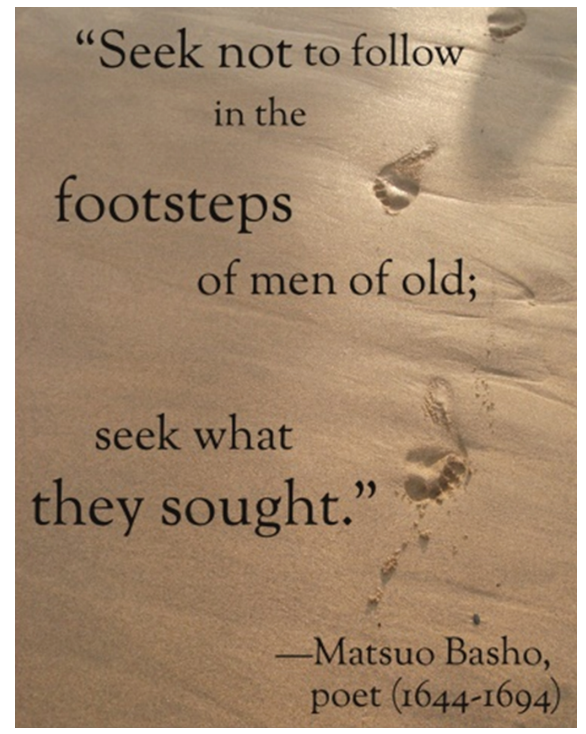

(0) The Author(s). 2021 Open Access This article is distributed under the terms of the Creative Commons Attribution 4.0 International License (https:// creativecommons.org/licenses/by-nc/4.0/), which permits unrestricted use, distribution, and non-commercial reproduction in any medium, provided you give appropriate credit to the original author(s) and the source, provide a link to the Creative Commons license, and indicate if changes were made. The Creative Commons Public Domain Dedication waiver (http://creativecommons.org/publicdomain/zero/1.0/) applies to the data made available in this article, unless otherwise stated. 